\title{
On a functional Fredholm integral equation, via the technique of nonexpansive operators
}

\section{MONICA LAURAN}

\section{ABSTRACT.}

In this paper we present one result relative to existence of solutions of the functional Fredholm integral equation with deviating argument by nonexpansive operators technique

$$
u(x, y)=f(x, y, g(u)(x, y))+\int_{a}^{b} \int_{a}^{b} K(x, y, s, t, u(s, t)) d s d t, \quad x, y \in[a, b]
$$

in a subset of a Banach space.

\section{REFERENCES}

[1] Berinde, V., Existence and approximation of solutions of some first order iterative differential equations, Miskolc Math. Notes, 11 (2010), No. 1, pp. 1326

[2] Berinde, V. and Lauran, M., Nonexpansive fixed point technique used for solve boundary value problem for fractional differential equations, Analele St. ale Univ. Al. I. Cuza Iasi, Seria Matematica, Tomul LVII, Supliment, 137 - 150, 2011

[3] Goebel, K. and Kirk, W. A., Topics in Metric Fixed Point Theory, Cambridge University Press, Cambridge, 1990

[4] Ishikawa, S., Fixed point and iteration of a nonexpansive mapping in a Banach space, Proc. Amer. Math. Soc., 59 (1976), No. 1, 65-71

[5] Lauran, M., Solution of first iterative differential equations, Analele Univ. din Craiova, 40 (2013), No. 1, 45-51

[6] Lauran, M., Existence results for some nonlinear integral equations, Miskolc Math. Notes, 13 (2012), No. 1, 67-74

[7] Lauran, M., Existence results from some integral equations with modified argument, General Mathematics, 19 (2011), No. 3, 85-92

[8] Lauran, M., Existence results for some differential equations with deviating argument, Filomat, 25 (2011), No. 2, 21-31

[9] Pachpatte, B. G., On Fredholm type integral equation in two variables, Diff. Eq. and Appl., 1 (2009), No. 1, 27-39

[10] Rus, I. A. and Petrusel, A. and Petrusel, G., Fixed point theory, Cluj University Press, 2008

DePARTMENT OF MATHEMATICS AND COMPUTER SCIENCE

Faculty of SCIENCES North University CEnTER at Baia Mare

TECHNICAL UNIVERSITY OF CLUJ-NAPOCA

VICTORIEI 76, 430122 BAIA MARE, ROMANIA

E-mail address: lauranmonica@yahoo.com

* Dedicated to Professor Emeritus Constantin Corduneanu on the occasion of his 85th birthday Received: 15.06.2013; In revised form: 01.08.2013; Accepted: 04.08.2013

2010 Mathematics Subject Classification. 45B05, 45D05, 47H10.

Key words and phrases. Functional integral equations, Fredholm equation, existence of solutions, nonexpansive mapping. 